\title{
Knowledge and attitudes regarding elective oocyte cryopreservation in undergraduate and medical students
}

\author{
Arnold M. Mahesan ${ }^{1 *}$, Seifeldin Sadek', Hadi Ramadan', Silvina Bocca', Anthea B. M. Paul ${ }^{2}$ and Laurel Stadtmauer ${ }^{1}$
}

\begin{abstract}
Background: To assess knowledge and attitudes regarding elective oocyte cryopreservation among female undergraduate students (UG) and medical students (MS) in Eastern Virginia.

Methods: An anonymous cross-sectional study surveying female UG at a local university and MS at our academic medical center in May of 2017. The survey contained questions on demographic information, interest in fertility preservation, and knowledge about age related changes in fertility.

Results: There were 74 of 102 female UG and 95 of 117 female MS who responded, for a response rate of 73 and $81 \%$ respectively. UG were significantly younger than MS ( 21.4 vs $26.8, p<0.001)$. Further, UG generally planned on conceiving at a younger age than MS (age 26-30 vs 31-35), and favored younger ages to consider oocyte cryopreservation (age 26-30 vs 31-35). Only a minority of both UG and MS were willing to undergo egg freezing at the current price of approximately $\$ 10,000$ (15\% vs $26 \%$ respectively, $p=0.044$ ). Moreover, $73 \%$ of students overall responded that they would be more likely to freeze oocytes if their employer paid. Notably, both UG and MS underestimated age of fertility decline.
\end{abstract}

Conclusion: Both UG and MS revealed a need for education on age-related changes in fertility. Most UG and MS would not undergo elective oocyte cryopreservation at the present cost but would consider it at a lower cost.

Keywords: Elective oocyte cryopreservation, Social fertility preservation, Undergraduates, Medical students

\section{Background}

The average age of first-time mothers in the United States increased by 1.4 years from 2000 to 2014, from 24.9 years to 26.3 years [1]. With improvement in assisted reproductive technology (ART) more women are seeking infertility treatment at advanced maternal ages. In the United States in 2015, 12,943 embryo transfers were performed in women aged $35-37$ years, and 18,429 were performed in women aged $>37$ years $[2,3]$.

The delay in childbearing is thought to stem from social and economic factors [4]. With the development of oocyte cryopreservation and the vitrification process, women who desire to postpone pregnancy can avoid the need for donor oocytes and can use their own eggs at a

\footnotetext{
* Correspondence: mahesaam@evms.edu

${ }^{1}$ Jones Institute for Reproductive Medicine, Eastern Virginia Medical School, 700 W Olney Rd, Norfolk, VA 23507, USA

Full list of author information is available at the end of the article
}

later age [5]. Both egg freezing and egg donation are costly, however technologies that allow preservation of fertility until later in life have increasingly entered the public eye $[6,7]$. The strong demand for these technologies is reflected by the recent offering of oocyte cryopreservation costs as an employee benefit by prominent companies such as Facebook and Apple [6].

Knowledge on elective oocyte freezing varies widely, even amongst physicians [7]. In a study of 410 Israeli undergraduate students, students overestimated women's chances of spontaneous pregnancy in all age groups. Only $11 \%$ of students knew that genetic motherhood is unlikely to be achieved from mid-40s onwards, unless using oocytes frozen in advance or donor oocytes from a younger donor. $[8,9]$. In another study of 328 university students in Northern California, 79\% were interested in learning about the current status of ovarian reserve, but

(c) The Author(s). 2019 Open Access This article is distributed under the terms of the Creative Commons Attribution 4.0 International License (http://creativecommons.org/licenses/by/4.0/), which permits unrestricted use, distribution, and reproduction in any medium, provided you give appropriate credit to the original author(s) and the source, provide a link to the Creative Commons license, and indicate if changes were made. The Creative Commons Public Domain Dedication waiver (http://creativecommons.org/publicdomain/zero/1.0/) applies to the data made available in this article, unless otherwise stated. 
only $29 \%$ would consider stopping professional pursuits to focus on conceiving [10].

UG and MS are at a stage in their lives where they are considering their future and career goals. Given the currently increased visibility and feasibility of elective oocyte cryopreservation technology, these students are increasingly faced with oocyte cryopreservation as an option that may influence their life and career decisions. We conducted the present study to explore knowledge and attitudes regarding elective oocyte cryopreservation among female undergraduate students and medical students in Eastern Virginia.

\section{Materials and methods}

We conducted an anonymous cross-sectional study surveying female undergraduate students at a local university and medical students at our academic medical center in December of 2017. Printed questionnaires developed by the authors of the study were distributed to students at the end of classes and completion was voluntary and confidential. Undergraduate surveys were administered in introductory biology classes, and medical school surveys were administered in fourth year full-class didactic sessions. These sessions were on general issues regarding life after graduation, and no background reading was given to the students. Surveys were handed only to students who indicated they desired to complete them. These students returned the surveys anonymously to a box before they left the classroom. The survey contained questions on demographic information, interest in fertility preservation, and knowledge about age related changes in fertility. (Additional file 1) The study was approved by the Eastern Virginia Medical School Institutional Review Board (IRB \#: 17.05-XX-0133).

Descriptive statistics for the answers to survey questions were calculated. Medical student responses were compared to undergraduate student responses. Continuous variables were compared using unpaired Student's t-test, and categorical variables were compared with Chi-squared test using SPSS ${ }^{\mathrm{mt}}$ (SPSS Statistical Software V.22.0, IBM, Armonk, NY). $P$ values of less than 0.05 were considered significant.

\section{Results}

\section{Population characteristics}

The characteristics of the population surveyed are presented in Table 1. One hundred sixty-nine of 219 female students chose to complete the survey, for an overall response rate of $77 \%$. This include 74 of 102 female undergraduates and 95 of 117 female medical students, for group specific response rates of 73 and $81 \%$ respectively. The mean age of all participants was $24+/-4.0$. The mean age of undergraduate students was $21.4+/-3.5$, which was significantly younger than the mean age of medical students, $26.8+/-2.3(p<0.00001)$.

Overall, $55 \%$ of participants were White, $17 \%$ were Asian, 15\% were African American, and 5\% were Hispanic/Latino. The most common religious denominations overall were Christian at $37 \%$ and non-religious at $34 \%$. Medical students differed significantly from undergraduates in race, with medical students having higher proportions of White (62\% vs $46 \%)$ and Asian (22\% vs $11 \%)$ and lower proportions of African American (12\% vs $19 \%$ ) and Hispanic/Latino students (1\% vs $11 \%), p=$ 0.00027 . Medical students also different significantly in religion, with a larger proportion identifying as Hindu/ Buddhist/other ( $18 \%$ vs $3 \%, p=0.011)$.

Only $4 \%$ of participants surveyed had children and $64 \%$ overall planned to have children. Significantly more medical students than undergraduates planned to have children, $80 \%$ vs. $53 \%(p=0.0001)$. For those who planned to have children, $33 \%$ of medical students planned on conceiving between age 31-35, whereas $40 \%$ of undergraduates planned on conceiving at the younger age of $26-30(p=0.022)$. Finally, $73 \%$ of participants overall felt no pressure from family to conceive or have children, with no significant difference between undergraduate and medical students.

\section{Personal decisions regarding oocyte cryopreservation}

Responses to questions on personal decisions regarding oocyte cryopreservation are presented in Table 2. Regarding which age to consider oocyte cryopreservation, $41 \%$ of undergraduates favored age $26-30$, whereas $48 \%$ of medical students favored the older age of 31-35 $(p=0.028)$. Sixty-two percent of students overall would consider oocyte cryopreservation for career reasons, $47 \%$ would consider it for medical reasons, and only $34 \%$ would consider it for social reasons, with no significant difference between medical students and undergraduates.

Undergraduates and medical students differed significantly in their willingness to undergo egg freezing at the current price $(\sim \$ 10,000), 15$ and $26 \%$ respectively ( $p=$ $0.044)$. The majority of students, $52 \%$, believed insurance should pay for oocyte cryopreservation and significantly more medical students, $11 \%$, believed the employer should pay in comparison to $0 \%$ of undergraduates $(p=$ 0.009 ). A large majority, $73 \%$ of students overall, believed that if an employer paid, they would be more likely to undergo oocyte cryopreservation.

We examined the data for significant correlations to other variables besides student type, and found that religion was associated with the decision to undergo oocyte cryopreservation. Seventy-nine percent of Christians and $76 \%$ of Non-religious participants believed that decreasing fertility with age would influence their decision to undergo oocyte cryopreservation. In comparison, only 
Table 1 Surveyed Population Characteristics

\begin{tabular}{|c|c|c|c|c|}
\hline & Total $(n=169)$ & Undergraduates $(n=74)$ & Medical students $(n=95)$ & $p$ value \\
\hline Mean Age (SD) & $24.0(4.0)$ & $21.6(3.5)$ & $26.8(2.3)$ & $<0.00001$ \\
\hline \multicolumn{4}{|l|}{ Race (\%) } & 0.00027 \\
\hline White & 55 & 46 & 62 & \\
\hline Hispanic/Latino & 5 & 11 & 1 & \\
\hline African American & 14 & 19 & 12 & \\
\hline Asian & 17 & 11 & 22 & \\
\hline Other & 7 & 12 & 3 & \\
\hline \multicolumn{4}{|l|}{ Religion (\%) } & 0.011 \\
\hline Christian & 37 & 39 & 36 & \\
\hline Catholic & 13 & 15 & 13 & \\
\hline Non-religious & 34 & 38 & 32 & \\
\hline Muslim & 2 & 1 & 4 & \\
\hline Hindu/buddhist/other & 11 & 3 & 18 & \\
\hline \multicolumn{4}{|l|}{ Have children (\%) } & 0.74 \\
\hline Yes & 4 & 4 & 5 & \\
\hline No & 96 & 95 & 95 & \\
\hline \multicolumn{4}{|l|}{ Plan to have children (\%) } & 0.0001 \\
\hline Yes & 65 & 53 & 80 & \\
\hline No & 20 & 27 & 8 & \\
\hline Unknown & 15 & 20 & 12 & \\
\hline \multicolumn{4}{|c|}{ Age plan to have first child (\%) } & 0.022 \\
\hline $21-25$ & 4 & 5 & 0 & \\
\hline $26-30$ & 30 & 41 & 21 & \\
\hline $31-35$ & 28 & 24 & 33 & \\
\hline $35-40$ & 2 & 0 & 4 & \\
\hline $40+$ & 1 & 0 & 1 & \\
\hline Unknown & 33 & 27 & 39 & \\
\hline \multicolumn{4}{|c|}{ Feel pressure from family to have child (\%) } & 0.46 \\
\hline Yes & 26 & 28 & 24 & \\
\hline No & 73 & 69 & 75 & \\
\hline
\end{tabular}

$48 \%$ of Catholics thought age would influence their decision $(p=0.039)$. Also, pressure from family to have a child was also significantly associated with the decision to cryopreserve, as $59 \%$ of participants who felt pressure thought they would consider oocyte cryopreservation compared with $41 \%$ who did not $(p=0.049)$.

\section{Knowledge about age-related changes in fertility}

Table 3 presents responses to questions assessing knowledge about age-related changes in fertility. Significantly more medical students (68\%) than undergraduates (59\%; $p=0.032$ ) believed they had some knowledge on these issues. When asked "At what age does natural fertility significantly decrease?", $38 \%$ of undergraduates answered between ages $36-40$ and $35 \%$ between ages $41-45$, as compared with $62 \%$ of medical students who answered more correctly between ages $36-40(p=0.001)$.

$55 \%$ of students who reported no prior knowledge and $62 \%$ of participants who reported moderate knowledge believed that age 46-50 was too old to have a child naturally, while $53 \%$ who claimed some (or little) prior knowledge thought age 41-45 was too old $(p=0.003)$. Further, $53 \%$ of undergraduates answered that age 46-50 is too old to have children naturally, while $48 \%$ of medical students answered age 41-45 ( $p=0.018)$.

Most students, $72 \%$ overall, agreed that decreased fertility with age influences their decision to freeze oocytes. Students were split evenly on the increased risk of miscarriage with age influencing their decision: 50\% answered "yes" with no significant difference between undergraduates and medical students. However, a 
Table 2 Personal Decisions Regarding Elective Oocyte Cryopreservation

\begin{tabular}{|c|c|c|c|c|}
\hline & Total $(n=169)$ & Undergraduates $(n=74)$ & Medical students $(n=95)$ & $p$ value \\
\hline \multicolumn{4}{|c|}{ Age would consider egg freezing } & 0.028 \\
\hline $21-25$ & 9 & 16 & 3 & \\
\hline $26-30$ & 28 & 41 & 19 & \\
\hline $31-35$ & 39 & 27 & 48 & \\
\hline $36-40$ & 8 & 5 & 11 & \\
\hline Above 40 & 1 & 1 & 1 & \\
\hline \multicolumn{4}{|c|}{ Would consider egg freezing for medical reasons } & 0.93 \\
\hline Yes & 47 & 47 & 44 & \\
\hline No & 53 & 51 & 49 & \\
\hline \multicolumn{4}{|c|}{ Would consider egg freezing for social reasons } & 0.62 \\
\hline Yes & 34 & 32 & 35 & \\
\hline No & 66 & 68 & 64 & \\
\hline \multicolumn{4}{|c|}{ Would consider egg freezing for career reasons } & 0.62 \\
\hline Yes & 63 & 60 & 64 & \\
\hline No & 37 & 39 & 36 & \\
\hline \multicolumn{4}{|c|}{ Would consider egg freezing at current price $(\sim \$ 10,000)$} & 0.044 \\
\hline Yes & 21 & 15 & 26 & \\
\hline No & 20 & 19 & 20 & \\
\hline At lower price & 57 & 66 & 46 & \\
\hline \multicolumn{4}{|c|}{ Who should pay for egg freezing } & 0.009 \\
\hline Self & 38 & 42 & 34 & \\
\hline Insurance & 52 & 55 & 50 & \\
\hline Employer & 6 & 0 & 11 & \\
\hline \multicolumn{4}{|c|}{ If employer paid, would be more likely to freeze eggs } & 0.68 \\
\hline Yes & 73 & 75 & 71 & \\
\hline No & 26 & 25 & 27 & \\
\hline
\end{tabular}

significant difference emerged when asked about the influence of increased risk of having a child with Down Syndrome with age on their decision: $47 \%$ of undergraduates answered "yes" compared with $59 \%$ of medical students $(p=0.039)$.

When asked about the minimum number of frozen oocytes at age 30 or age 40 likely to result in a live birth, there was no significant difference between undergraduates and medical students. For age 30, 38\% of students overall selected $11-20$ oocytes. For age $40,30 \%$ of students overall selected $21-30$ oocytes, while only $25 \%$ answered correctly that $40+$ oocytes were required [11].

\section{Discussion}

As elective oocyte cryopreservation takes increasing prominence in society and medicine, we sought to compare responses between medical students and undergraduates, who as groups differed significantly in age, race, and religion (Table 1). Further, undergraduates vary in their exposure to and knowledge of reproductive medicine.

Most undergraduate and medical students would not consider elective oocyte preservation at the present time. This is in line with previous studies, where the cost of oocyte preservation is the limiting factor in younger women's ability to undergo the procedure [10, 12]. Even though the majority of both groups would not undergo oocyte cryopreservation, undergraduates were more price-sensitive at the current price. This might be influenced by medical students' perception of future earning potential, or desire to preserve their fertility in a long educational pathway.

A significant majority of women in our study would be more likely to consider elective oocyte cryopreservation if their employer paid for it. Well-known companies have begun a trend toward this in the past few years. According to media reports, starting January 1, 2015, Apple $^{\text {TM }}$ was willing to pay up to $\$ 20,000$ per employee for oocyte cryopreservation and storage for all full-time 
Table 3 Knowledge about Age-Related Changes in Fertility

\begin{tabular}{|c|c|c|c|c|}
\hline & Total $(n=169)$ & Undergraduates $(n=74)$ & Medical students $(n=95)$ & $p$ value \\
\hline \multicolumn{4}{|c|}{ Prior knowledge about egg freezing (\%) } & 0.032 \\
\hline None & 20 & 30 & 14 & \\
\hline Some knowledge & 64 & 59 & 68 & \\
\hline Moderate knowledge & 13 & 9 & 16 & \\
\hline Very knowledgeable & 1 & 0 & 2 & \\
\hline \multicolumn{4}{|c|}{ At what age does fertility significantly decrease? (\%) } & 0.001 \\
\hline Age 30-35 & 16 & 15 & 15 & \\
\hline Age $36-40$ & 48 & 38 & 62 & \\
\hline Age $41-45$ & 27 & 35 & 16 & \\
\hline Age $46-50$ & 7 & 11 & 4 & \\
\hline \multicolumn{4}{|c|}{ What age is too old to have a child naturally? (\%) } & 0.018 \\
\hline Age 30-35 & 2 & 4 & 0 & \\
\hline Age $36-40$ & 9 & 8 & 9 & \\
\hline Age $41-45$ & 44 & 32 & 48 & \\
\hline Age 46-50 & 41 & 53 & 32 & \\
\hline \multicolumn{4}{|c|}{ Does the fact of increased miscarriage risk with age influence your decision to freeze eggs? (\%) } & 0.72 \\
\hline Yes & 50 & 51 & 48 & \\
\hline No & 50 & 49 & 51 & \\
\hline \multicolumn{4}{|c|}{ Does the increased risk of Down syndrome with age influence your decision to freeze eggs? (\%) } & 0.039 \\
\hline Yes & 54 & 47 & 59 & \\
\hline No & 45 & 51 & 35 & \\
\hline \multicolumn{4}{|c|}{ What is the minimum number of frozen eggs at age 30 likely to result in a live birth? (\%) } & 0.078 \\
\hline $5-10$ oocytes & 18 & 11 & 21 & \\
\hline 11-20 oocytes & 38 & 34 & 40 & \\
\hline 21-30 oocytes & 26 & 34 & 19 & \\
\hline $31-40$ oocytes & 8 & 9 & 7 & \\
\hline $40+$ oocytes & 6 & 7 & 5 & \\
\hline \multicolumn{4}{|c|}{ What is the minimum number of frozen eggs at age 40 likely to result in a live birth? (\%) } & 0.731 \\
\hline 5-10 oocytes & 4 & 5 & 7 & \\
\hline 11-20 oocytes & 12 & 9 & 13 & \\
\hline 21-30 oocytes & 30 & 26 & 32 & \\
\hline $31-40$ oocytes & 25 & 27 & 22 & \\
\hline $40+$ oocytes & 25 & 26 & 25 & \\
\hline
\end{tabular}

and part-time employees. Facebook ${ }^{\mathrm{Tm}}$ introduced a similar benefit for its employees in the United States in January 2014 and pays up to $\$ 20,000$ for both medical and non-medical oocyte cryopreservation [13, 14].

However, oocyte preservation is not a guarantee of future fertility. Donor egg studies show that age of the oocyte donor is a significant predictor of pregnancy success and is a major factor in selecting prospective candidates [15]. There may be also deficiencies created by the freezing process itself [5]. In 2015 the pregnancy rate was $52.7 \%$ for frozen donor egg transfer in comparison to $65.9 \%$ for fresh donor egg transfer [16].
In our study medical students favored undergoing cryopreservation at ages 31-35 while most undergraduates would undergo it at 26-30. This may have reflected the differing age of each group, where each group thought they would consider freezing about 5-10 years in the future. However, literature shows that even in younger women (i.e., < 38 years old), the clinical pregnancy rate (CPR) per thawed oocyte is low, ranging from only $4.5-12 \%$ [17] and the likelihood of success decreases with age at freezing. To have a greater than $50 \%$ chance of live birth at age $<35$, a woman must freeze at least 10 oocytes. At age 40, this number increases to 40 
oocytes [11]. Women in our study consistently underestimated this number, and only $25 \%$ of women selected the correct number of eggs.

Oocyte preservation may be a reasonably effective method of fertility preservation if adequate numbers of eggs are frozen at a younger age, but due to the expense, cost-effectiveness is important to discuss when translating these findings to patient counseling. The cost-effectiveness assessment adds the question of whether frozen oocytes would actually be used. Cobo et al. reported that of 1469 patients undergoing oocyte cryopreservation, only 137 $(9.3 \%)$ returned to use the frozen oocytes at a mean age of 39.2 (95\% CI 39.0-40.1) [18]. The most cost-effective strategy varies depending on age of desired childbirth. Indeed, at a relatively younger age, a woman would be likely to become pregnant on her own and would not require frozen oocytes. Due to this, some suggest the most cost-effective strategy is to encourage woman to not delay childbearing [19]. Following from this reasoning Mesen et al. find that over a 7 year horizon oocyte cryopreservation provides the greatest improvement in probability of live birth compared with no action when performed at age 37 years $(51.6 \%$ vs. 21.9). [4]. However, in absolute terms, the younger the age of egg freezing, the more successful the pregnancy outcome [20].

Assuming a woman will desire pregnancy at an older age where natural conception is less successful, an important question is whether undergoing an IVF cycle at that age is more cost-effective than using frozen oocytes from her younger age. A model developed by Devine et al. assuming pregnancy attempt at age 40 showed that the most cost-effective approach was attempting spontaneous conception by intercourse for 6 months then using oocytes that were frozen by age 35 . Using frozen oocytes was more cost effective than attempting IVF at age 40 for two cycles. When age of oocyte cryopreservation was varied, the approach using frozen oocytes instead of undergoing fresh IVF remained more cost effective up to age 38. After this age, it was not cost-effective to freeze oocytes [21].

When asked about the age at which fertility significantly decreases, a large proportion of undergraduates, $35 \%$, believed that this occurred at age $41-45$. The majority of medical students believed this occurred at a more realistic 36-40. However, in reality, fecundity begins to decrease at age 30; in addition, it has been demonstrated that the chance of not conceiving a first child within 1 year increases approximately 6-fold when women over 30 years of age [20]. In recent decades, numerous reports have confirmed that the probability of a live birth decreases distinctly after the age of 35 , especially with ART. [20]

This overly optimistic impression of late and very late pregnancy success may be a result, at least partially, from media coverage of such pregnancies. In an analysis of British media portrayals of older mothers, a preponderance of coverage relating to celebrities was identified. Delayed childbearing was represented positively, as part of a life plan allowing women to have the "best of both worlds," and the media did not acknowledge age as an obstacle to pregnancy [22]. A study on public perception showed that advanced maternal age was not perceived as a risk factor and that the increased risks and complications were not elaborated on by the media [23].

Our study has several limitations. Our population size is small but included a mixture of science undergraduates, non-science undergraduates, and medical students. We were able to compare students at different points in their lives and education to understand similarities and differences in perspectives. However, we were limited to students and our findings may not generalize to the population not pursuing formal education. Further, our study was limited to a local population in Eastern Virginia and a larger nationwide survey to undergraduates and medical student would better represent the population trend.

\section{Conclusion}

Most undergraduate and medical students would not undergo elective oocyte cryopreservation at the present cost. However, a significant majority of women in our study would be more likely to consider it at a lower cost or if their employer paid for it. We identified a need for education on age-related changes in fertility in both undergraduates and medical students, as students tended to overestimate the age of fertility decline. This may suggest a wider need for public education, particularly regarding efficacy of cryopreservation with increasing age, cost-effectiveness of cryopreservation, and age-related fertility decline.

\section{Additional file}

Additional file 1: Oocyte Cryopreservation (egg freezing) Survey.

(DOCX 17 kb)

\section{Abbreviations \\ ART: assisted reproductive technology; MS: medical students; UG: undergraduate students}

\section{Acknowledgements}

Not applicable.

\section{Funding}

No funding.

Availability of data and materials

The datasets used and/or analyzed during the current study are available from the corresponding author on reasonable request. 


\section{Authors' contributions}

AMM and LS: Protocol/project development. Data collection or management. Data analysis. Manuscript writing/editing. SS: Data collection and management. Data analysis. Manuscript writing/editing. HR: Manuscript writing/editing/. SB: Data collection and management. Manuscript writing/ editing. ABMP: Data collection or management. Data analysis. All authors read and approved the final manuscript.

\section{Ethics approval and consent to participate}

The study was approved by the Eastern Virginia Medical School Institutiona Review Board (IRB \#: 17.05-XX-0133).

Printed questionnaires were distributed to students at the end of classes and completion was voluntary and confidential.

Surveys were handed only to students who indicated they desired to complete them.

These students returned the surveys anonymously to a box before they left the classroom

\section{Consent for publication}

All surveys were anonymous and unidentifiable. Consents were obtained.

\section{Competing interests}

The authors declare that they have no competing interests.

\section{Publisher's Note}

Springer Nature remains neutral with regard to jurisdictional claims in published maps and institutional affiliations.

\section{Author details}

'Jones Institute for Reproductive Medicine, Eastern Virginia Medical School, 700 W Olney Rd, Norfolk, VA 23507, USA. ${ }^{2}$ University of Ottawa, Ottawa, ON Canada.

Received: 5 November 2018 Accepted: 1 April 2019

Published online: 10 April 2019

\section{References}

1. Mathews TJ, Hamilton BE. Mean age of mothers is on the rise: United States, 2000-2014. NCHS data brief. United States; 2016. p. 1-8.

2. Sunderam S, Kissin DM, Crawford SB, Folger SG, Jamieson DJ, Warner L, et al. Assisted reproductive Technology surveillance — United States, 2014. MMWR Surveill Summ. 2017;66:1-24.

3. Sunderam S, Kissin DM, Crawford SB, Folger SG, Boulet SL, Warner L, et al. Assisted reproductive Technology surveillance - United States, 2015. MMWR Surveill Summ. United States. 2018;67:1-28.

4. Mesen TB, Mersereau JE, Kane JB, Steiner AZ. Optimal timing for elective egg freezing. Fertil Steril Elsevier Inc. 2015;103:1551-1556.e4.

5. Kuwayama M. Highly efficient vitrification for cryopreservation of human oocytes and embryos: the Cryotop method. Theriogenology. 2007;67:73-80.

6. Sydell L. Silicon Valley companies add new benefit for women: eggfreezing: Npr; 2014.

7. Yu L, Peterson B, Inhorn MC, Boehm JK, Patrizio P. Knowledge, attitudes, and intentions toward fertility awareness and oocyte cryopreservation among obstetrics and gynecology resident physicians. Hum Reprod. 2016; 31:403-11.

8. de Groot M, Dancet E, Repping S, Goddijn M, Stoop D, van der Veen F, et al. Perceptions of oocyte banking from women intending to circumvent agerelated fertility decline. Acta Obstet Gynecol Scand. 2016;95:1396-401.

9. Hashiloni-Dolev Y, Kaplan A, Shkedi-Rafid S. The fertility myth: Israel students knowledge regarding age-related fertility decline and late pregnancies in an era of assisted reproduction technology. Hum Reprod. 2011;26:3045-53

10. Bavan B, Porzig E, Baker VL. An assessment of female university students' attitudes toward screening technologies for ovarian reserve. Fertil Steril Elsevier Ltd. 2011;96:1195-9.

11. Goldman RH, Racowsky C, Farland LV, Munne S, Ribustello L, Fox JH. Predicting the likelihood of live birth for elective oocyte cryopreservation: a counseling tool for physicians and patients. Hum Reprod England. 2017;32: 853-9.

12. Kudesia R, Chernyak E, McAvey B. Gaps in fertility knowledge among female medical trainees [357]. Obstet Gynecol. 2015;125.
13. Withnall RDJ, Morris L. Career or family planning? Oocyte cryopreservation for UK servicewomen. J R Army Med Corps England. 2016:3-4.

14. Baylis F. Left out in the cold: arguments against non-medical oocyte cryopreservation. J Obstet Gynaecol Canada Elsevier Masson SAS. 2015;37:64-7.

15. Cohen MA, Lindheim SR, Sauer MV. Donor age is paramount to success in oocyte donation. Hum Reprod. England. 1999;14:2755-8.

16. Centers for Disease Control, and Prevention AS for R, Medicine $S$ for ART. Assisted Reproductive Technology National Summary Report. 2015;2017:1-80.

17. Practice T, Medicine R, Technology R. Mature oocyte cryopreservation: a guideline. Fertil Steril American Society for Reproductive Medicine. 2013;99:37-43.

18. Cobo A, Garcia-Velasco JA, Coello A, Domingo J, Pellicer A, Remohi J. Oocyte vitrification as an efficient option for elective fertility preservation. Fertil Steril United States. 2016;105:755-764.e8.

19. Hirshfeld-Cytron J, Grobman WA, Milad MP. Fertility preservation for social indications: a cost-based decision analysis. Fertil Steril. Elsevier Inc. 2012:97:665-70.

20. Broekmans FJ, Soules MR, Fauser BC. Ovarian aging: mechanisms and clinical consequences. Endocr Rev. 2009:30:465-93.

21. Devine K, Mumford SL, Goldman KN, Hodes-Wertz B, Druckenmiller S, Propst AM, et al. Baby budgeting: oocyte cryopreservation in women delaying reproduction can reduce cost per live birth. Fertil Steril United States. 2015; 103:1442-6.

22. Mills TA, Lavender R, Lavender T. "Forty is the new twenty": an analysis of British media portrayals of older mothers. Sex Reprod Healthc Elsevier BV. 2015;6:88-94.

23. Shaw RL, Giles DC. Motherhood on ice? A media framing analysis of older mothers in the UK news. Psychol Health. 2009:24:221-36.

\section{Ready to submit your research? Choose BMC and benefit from:}

- fast, convenient online submission

- thorough peer review by experienced researchers in your field

- rapid publication on acceptance

- support for research data, including large and complex data types

- gold Open Access which fosters wider collaboration and increased citations

- maximum visibility for your research: over $100 \mathrm{M}$ website views per year

At BMC, research is always in progress.

Learn more biomedcentral.com/submissions 